\title{
Psoríase Eritrodérmica: relato de caso e revisão bibliográfica
}

\section{Erythrodermic psoriasis: a case report and literature review}

Ana Carolina A de F Ferreira1, Fernanda SA dos Anjos¹, Patrícia M Yoshino², Lívia S Hall², Simone CC Pinto ${ }^{3}$, Ricardo B Lima ${ }^{4}$

\begin{abstract}
RESUMO
A eritrodermia é uma síndrome rara, responsável por eritema e descamação difusos, que acometem mais de 80 ou $90 \%$ da superfície corporal. É potencialmente grave, devido à associação com distúrbios hidroeletrolíticos e à colonização bacteriana. Entre as causas etiológicas estão presentes: doenças dermatológicas primárias, reação alérgica a certas drogas, doenças sistêmicas, além de neoplasias. No presente relato de caso, ilustramos um exemplo de eritrodermia de instalação grave e aguda, inicialmente tratado com corticoterapia sistêmica. O exame histopatológico da pele indicou o diagnóstico de psoríase eritrodérmica, que respondeu bem ao tratamento com ciclosporina, acitretina e etanercepte. Com base nesse relato, foi realizada uma revisão da literatura sobre as causas de dermatite esfoliativa e discutido o manejo de casos graves de psoríase.
\end{abstract}

Palavras-chave: Dermatite Esfoliativa. Psoríase. Ciclosporina. Acitretina. Agentes Biológicos.

\section{Introdução}

A eritrodermia ou dermatite esfoliativa, é uma síndrome definida por eritema e descamação difusos, que acometem mais de 80 ou $90 \%$ da superfície corporal e pode cursar com prurido ${ }^{1,2,3}$ Atinge apenas um a 71/100.000 novos pacientes, ${ }^{4}$ com predomínio masculino de 2 a 4:1 em relação a mulheres e cujo início ocorre aos 52 anos, em média. ${ }^{5}$ Embora rara, a eritrodermia é potencialmente grave e 10 a $30 \%$ dos $\operatorname{casos}^{6}$ permanece com etiologia desconhecida.
A descamação predispõe à perda hidroeletrolítica e proteica, além da colonização bacteriana. Em fase avançada, acompanha-se de destruição dos anexos, com alopecia generalizada e distrofia ungueal. ${ }^{1,3}$

Apesar de a síndrome ser mais comum em homens e idosos, ${ }^{4}$ a pandemia pelo HIV levou à sua maior incidência em grupos mais jovens. ${ }^{3}$ Entre as possíveis etiologias, devem ser cogitadas não apenas doenças dermatológicas primárias, mas também, reação alérgica a certas drogas, doenças sistêmicas, além de neoplasias. ${ }^{1-4}$ Psoríase e reações a drogas são elencadas
1. Graduada em Medicina, Universidade Federal do Estado do Rio de Janeiro (UNIRIO) - Rio de Janeiro (RJ), Brasil.

2. Residente de Clínica Médica do Hospital Universitário Gaffrée e Guinle da UNIRIO.

3. Médica, preceptora da graduação e residência médica da Enfermaria de Clínica Médica A, plantonista e coordenadora do plantão geral. Hospital Universitário Gaffrée e Guinle da UNIRIO.

4. Professor Adjunto do Serviço de Dermatologia do Hospital Universitário Gaffrée e Guinle da UNIRIO.
Correspondência: Universidade Federal do Estado do Rio de Janeiro (UNIRIO) Escola de Medicina e Cirurgia Hospital Universitário Gaffrée e Guinle Rua Silva Ramos, no 32, Tijuca, Rio de Janeiro Email: anandorinho@ hotmail.com

Artigo recebido em 24/08/2013 Aprovado para publicação em 21/02/2014 
como as principais etiologias. Entre os estudos brasileiros, Kondo e colaboradores, ${ }^{4}$ verificaram prevalência de 18,97\% entre 58 pacientes para ambas as causas; Vasconcellos e colaboradores ${ }^{2}$ observaram $44,9 \%$ para psoríase e 7,3\% para farmacodermias entre 249 indivíduos, enquanto Fernandes e colaboradores ${ }^{1}$ encontraram a psoríase em $38,82 \%$ e eczema de contato por drogas em 10,59\% de 170 pacientes. Porém, nem todos os estudos são consoantes com esses dados. Conforme se eleva a faixa etária, outras causas podem se destacar, como as malignidades subjacentes, destacadas no estudo de Salami e colaboradores. ${ }^{3} \mathrm{Na}$ tabela 1 reunimos as peculiaridades clínicas e laboratoriais das principais etiologias em adultos:

Além dos aspectos clínicos, exames laboratoriais e radiológicos, a avaliação histopatológica é fundamental para se especificar o diagnóstico. Na Tabela 2, estão descritos os principais achados em doenças causadoras de eritrodermia:

O presente trabalho aborda um caso de eritrodermia de difícil manejo, conduzido inicialmente como farmacodermia, cujo tratamento adequado só foi possível após o diagnóstico histopatológico de psoríase eritrodérmica.

\section{Relato de caso}

Paciente do sexo feminino, 35 anos, branca, relatava começo do quadro com surgimento de pápulas pruriginosas paraesternais. Foi medicada com ivermectina oral e permetrina tópica, devido à hipótese diagnóstica de escabiose. Após três dias, apresentou febre, eritema e edema generalizados. Procurou serviço de emergência, sendo medicada com prometazina intravenosa, deltametrina tópica e banho com permanganato de potássio. Porém, permaneceu com febre e evoluiu com descamação difusa, poupando apenas mucosas.

Foi admitida no CTI do Hospital de Clínicas da Penha, em 06/12/2012, com hipótese inicial de sepse cutânea associada à farmacodermia. Durante a internação, a paciente recebeu doses elevadas de hidrocortisona endovenosa, além de múltiplos esquemas antimicrobianos de amplo espectro. Contudo, a descamação persistiu e surgiram alopecia difusa e distrofia ungueal. Tentativas de redução do corticoide provocavam exacerbação do quadro. Realizou-se biópsia cutânea, mas o resultado foi inconclusivo.

A paciente foi transferida estável para o Hospital Universitário Gaffrée e Guinle em 28/02/2013.
Negava erupções cutâneas prévias, atopia, manifestações articulares e casos familiares de doenças dermatológicas. Ao exame, notavam-se eritema e descamação brancacenta, na face, couro cabeludo, tronco, membros e nas regiões palmo-plantares, com menor intensidade no dorso. No couro cabeludo e supercílios apresentava alopecia difusa, com rarefação acentuada dos pelos. Nas unhas observavam-se hiperceratose subungueal e tonalidade acastanhada (Figura 1). Não havia alterações nas mucosas ocular, oral e genital. Não foram identificadas febre, adenomegalias, sintomas articulares ou visceromegalias. A paciente apresentava tremor essencial e taquicardia de $110 \mathrm{bpm}$.

As sorologias para HTLV-1 e HIV e a pesquisa de células de Sezary no sangue periférico foram negativas e os demais exames de sangue, normais.

A urinocultura foi positiva para Klebsiella pneumoniae. O swab nasal foi positivo para Staphylococcus aureus meticilo-resistente (MRSA).

A tomografia computadorizada de tórax, abdômen e pélvica não evidenciou massas nem linfonodomegalias.

O exame histopatológico da biópsia cutânea revelou: hiperceratose, paraceratose e acúmulos de neutrófilos na camada córnea (microabscessos de Munro); hipogranulose e acantose, com alongamento das cristas interpapilares. Na derme superior, verificava-se edema, ectasia vascular, discreta queda pigmentar, além de infiltrado inflamatório constituído por linfócitos e neutrófilos compatíveis com psoríase (Figura 2). De acordo com o exame clínico e o resultado da biópsia, concluímos tratar-se de psoríase eritrodérmica.

Diante dos resultados da urinocultura e de picos febris registrados posteriormente, iniciou-se a administração de ciprofloxacino EV. Foi introduzido prednisona $120 \mathrm{mg} /$ dia $\mathrm{VO}$ (dose correspondente à de hidrocortisona EV usada no Hospital de Clínicas da Penha) e foi acrescentada ciclosporina $100 \mathrm{mg} / \mathrm{dia}$. Após sete dias do início de ciclosporina, ocorreu melhora da descamação. Prosseguiu-se o tratamento aumentando a dose de ciclosporina para $200 \mathrm{mg} / \mathrm{dia}$ e reduzindo progressivamente a dose do corticoide. A paciente evoluiu com melhora, apesar de períodos de piora nos primeiros dias, associados às reduções do corticoide. Transcorridos 40 dias, adicionou-se acitretina 30mg/dia ao esquema terapêutico. Após 60 dias de internação, a paciente obteve alta para acompanhamento ambulatorial. Depois de 90 dias do co- 


\section{Tabela 1. Causas de eritrodermia e correlação clinico-laboratorial $1,2,6,7$}

\begin{tabular}{|c|c|}
\hline Etiologia & Particularidades Clínico-Laboratoriais \\
\hline Psoríase eritrodérmica & $\begin{array}{l}\text { Possíveis episódios prévios de lesões em placas } \\
\text { Eritema intenso e esfoliação difusos } \\
\text { Alopécia } \\
\text { Alterações ungueais } \\
\text { Manifestações sistêmicas como artrite } \\
\text { Aumento de ácido úrico, VHS, PCR e } \alpha 2 \text {-globulina }\end{array}$ \\
\hline Farmacodermia & $\begin{array}{l}\text { Início e término associados ao uso de drogas como sulfonamidas, anticonvulsivantes, alopurinol, } \\
\text { pirazolonas e antirretrovirais } \\
\text { Acometimento de mucosas } \\
\text { Síndrome de Steven-Johnson: envolvimento }<10 \% \text { de área corporal } \\
\text { Necrólise Epidérmica Tóxica: envolvimento }>30 \% \text { de área corporal }\end{array}$ \\
\hline Dermatite atópica & $\begin{array}{l}\text { História familiar de atopias } \\
\text { Prurido intenso sempre presente } \\
\text { Áreas eritematocrostosas na infância evoluem para papulodescamativas na adolescência } \\
\text { Tendência à atenuação com a idade }\end{array}$ \\
\hline Dermatite de contato & $\begin{array}{l}\text { Associada a aplicação e suspensão de certas substâncias, geralmente alcalinas ou ácidas fracas. } \\
\text { Lesões em locais expostos ao alérgeno: mãos, pés e rosto } \\
\text { Eritema, descamação, por vezes, vesículas e bolhas }\end{array}$ \\
\hline $\begin{array}{l}\text { Linfomas cutâneos } \\
\text { primários }\end{array}$ & $\begin{array}{l}\text { Micose Fungoide: Adultos com idade mediana de } 55 \text { anos } \\
\text { Placas eritemato-descamativas recorrentes com evolução em nódulos violáceos que podem ulcerar } \\
\text { Sindrome de Sèzary: possível variante leucêmica de Micose Fungoide } \\
\text { Prurido intenso e descamação generalizada } \\
\text { Linfonodo/hepato/esplenomegalia } \\
\geq 1.000 \text { células de Sézary (linfócitos atípicos) por } \mathrm{mm}^{3} \text { no sangue periférico } \\
\text { Leucemia/ Linfoma de células T do adulto: Infecção pelo HTLV - } 1 \text { por mais de } 20 \text { anos } \\
\text { Formas: indolente, crônica (sobrevida maior), linfomatosa e aguda (sobrevida de até } 1 \text { ano) } \\
\text { Placas e pápulas múltiplas e generalizadas, com tumores nas formas mais agressivas } \\
\text { Elisa positivo para Anti - HTLV - } 1\end{array}$ \\
\hline Dermatite seborreica & $\begin{array}{l}\text { Crônica e recorrente } \\
\text { Associada a estímulo androgênico, hipersecreção glandular e alterações qualitativas do sebo } \\
\text { Áreas ricas em glândulas sebáceas, como:couro cabeludo, face e flexuras }\end{array}$ \\
\hline Ptiríase rubra & $\begin{array}{l}\text { Possível episódio infeccioso prévio } \\
\text { Eritema flexural, seguido de eritema palmo plantar até a eritrodermia } \\
\text { Ceratodermia palmo-plantar alaranjada }\end{array}$ \\
\hline Pênfigo foliáceo & $\begin{array}{l}\text { História de vesículas e bolhas com sinal de Nikolsky positivo } \\
\text { Pele úmida } \\
\text { Odor de ninho de rato } \\
\text { Anticorpos anti - desmogleínas }\end{array}$ \\
\hline Lupus subagudo & $\begin{array}{l}\text { Lesões cutâneas policíclicas, anulares ou psoriasiformes, generalizadas ou não. } \\
\text { Fotossensibilidade marcante. } \\
\text { Manifestações sistêmicas discretas } \\
\text { Anticortpos Anti - Ro e Anti - La positivos }\end{array}$ \\
\hline Sarna crostosa & $\begin{array}{l}\text { Intenso prurido com ou sem exarcebação noturna. } \\
\text { Lesões acinzentadas e ceratósicas entre os dedos das mãos. } \\
\text { Pesquisa direta em escamas de pele - positiva para Sarcoptes scabiei }\end{array}$ \\
\hline $\begin{array}{l}\text { Manifestações } \\
\text { paraneoplásicas }\end{array}$ & $\begin{array}{l}\text { Carcinoma brônquico (principalmente). Carcinoma epidermóide e adenocarcinoma de pulmão. } \\
\text { Carcinoma epidermóide de nasofaringe }\end{array}$ \\
\hline
\end{tabular}


Tabela 2. Causas de eritrodermia e correlação histopatológical ${ }^{1,2,6,7}$

\begin{tabular}{|c|c|}
\hline Etiologia & Histopatologia \\
\hline \multirow[t]{5}{*}{ Psoríase eritrodérmica } & Hiper e paraceratose \\
\hline & Ausência de granulose \\
\hline & Ectasia de capilares e edema das papilas dérmicas \\
\hline & Acantose regular dos cones intrapapilares \\
\hline & Polimorfonucleares e linfócitos T abaixo do estrato córneo \\
\hline \multirow[t]{5}{*}{ Ptiríase rubra pilar } & Orto e paraceratose vertical e horizontal \\
\hline & Acantose com ou sem células disceratósicas \\
\hline & Discreta espongiose \\
\hline & Hipergranulose focal ou confluente \\
\hline & Na derme, linfócitos e histiócitos \\
\hline \multirow[t]{3}{*}{ Dermatiteseborreica } & Hiperplasia psoriasiforme \\
\hline & Infiltrado inflamatório com linfócitos e histiócitos \\
\hline & Paraceratose ao redor dos óstios foliculares \\
\hline \multirow[t]{4}{*}{ Linfoma cutâneo } & Hiperceratose \\
\hline & Acantose \\
\hline & Microabscessos de Pautrier (células atípicas linfo-histiocitárias na camada Malpighiana) \\
\hline & Infiltrado linfocítico com núcleo cerebriforme \\
\hline Farmacodermia & Compatíveis com eritema polimorfo e nodoso. \\
\hline Pênfigo foliáceo & Bolha acantolítica epidérmica alta na região subcórnea ou granulosa \\
\hline
\end{tabular}
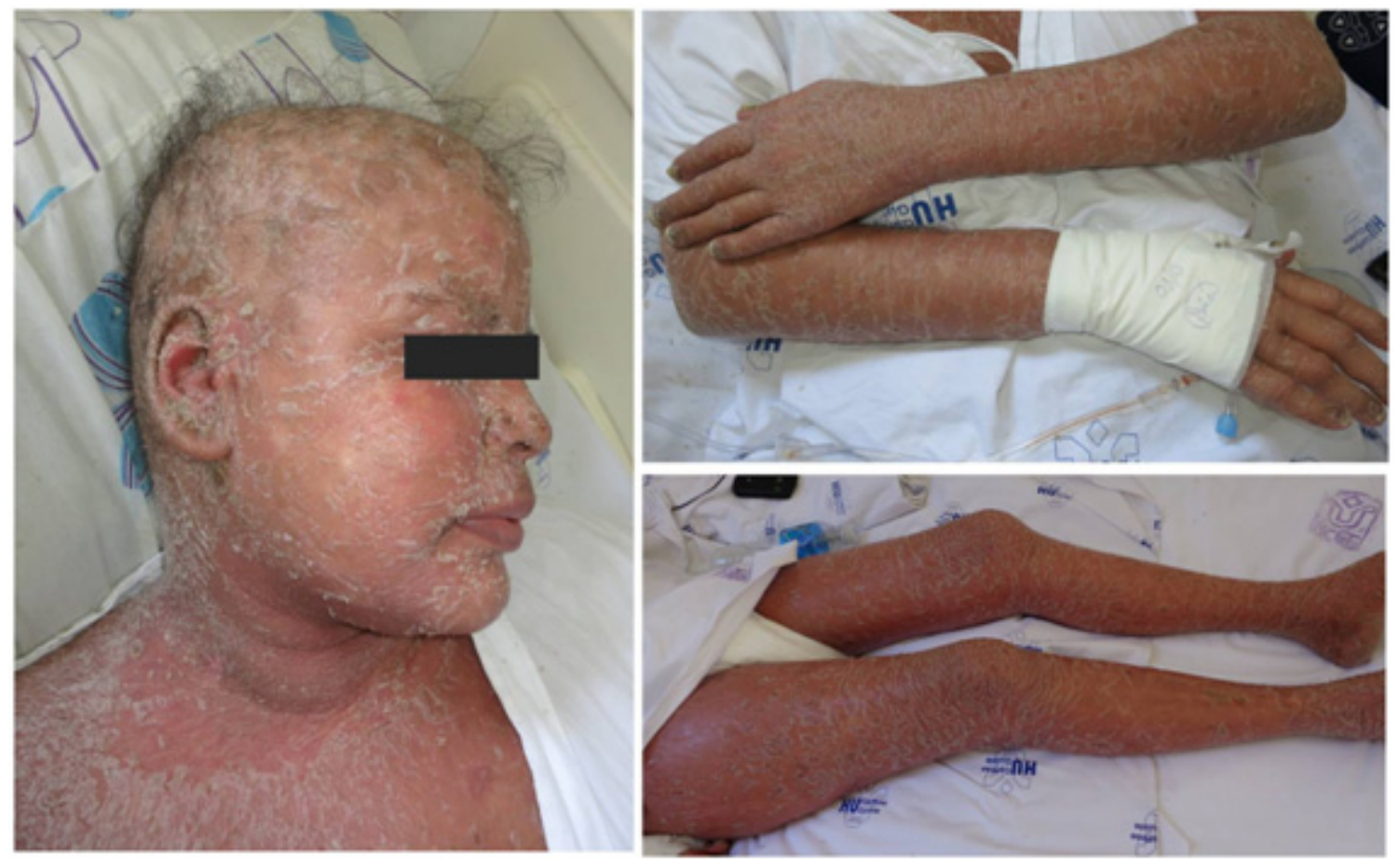

Figura 1: Paciente com alopecia, eritema e descamação difusos, no sexto dia de internação no HUGG, antes do início do tratamento. 


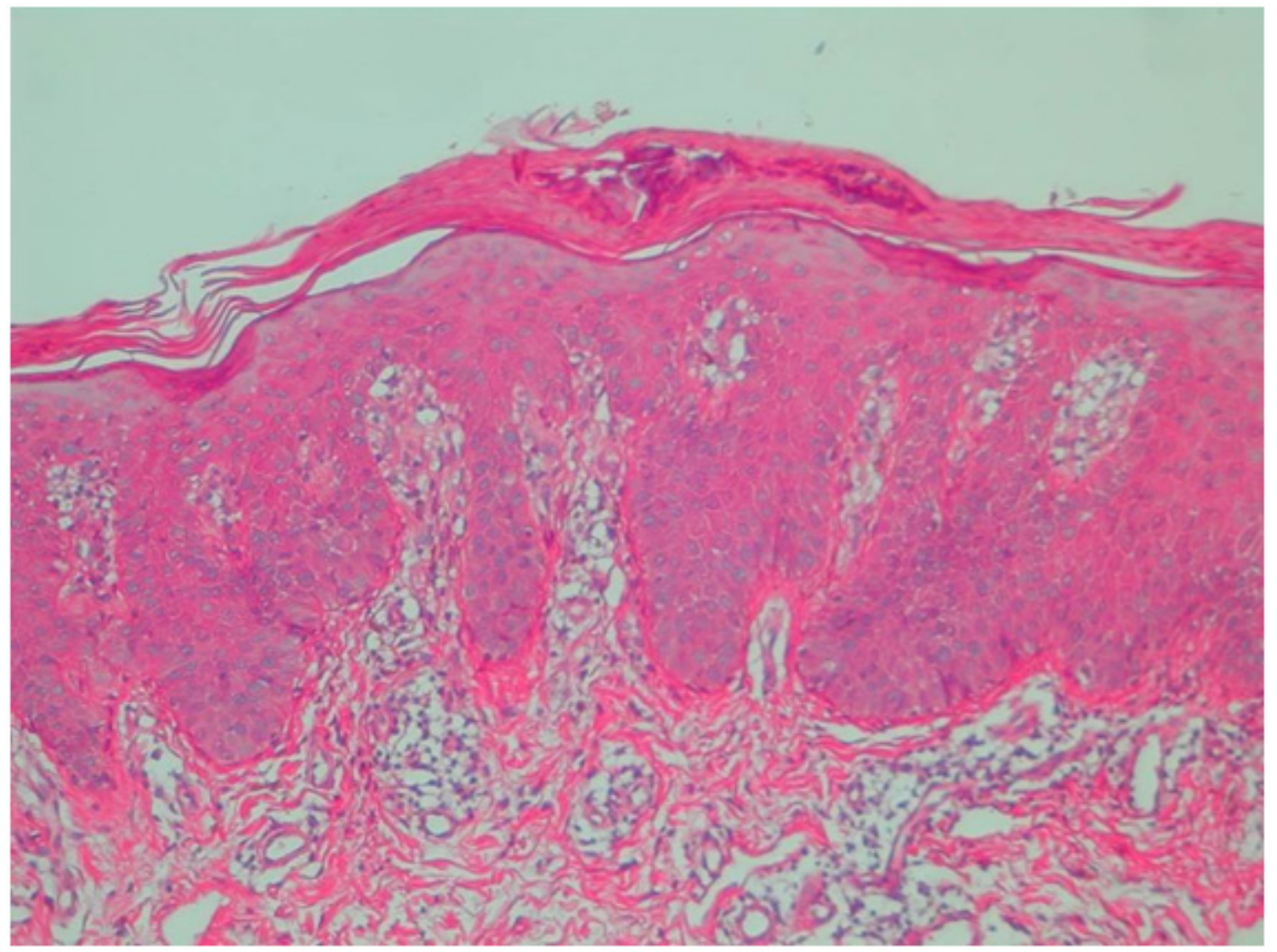

Figura 2: Na epiderme: hiperceratose, paraceratose, microabcesso de Munro (grupamentos de neutrófilos), acantose regular dos cones interpapilares e atrofia das áreas suprapapilares. Na derme: alongamento dos cones interpapilares, com capilares dilatados e tortuosos. Coloração pela HE, com aumento de 100X.

meço do tratamento, estando em uso de prednisona $20 \mathrm{mg} / \mathrm{dia}$, ciclosporina $200 \mathrm{mg} / \mathrm{dia}$ e acitretina $30 \mathrm{mg} /$ dia, a paciente mantinha a melhora da doença, exibindo crescimento de fâneros e boa regeneração cutânea (Figura 3). Porém, surgiu artralgia nos punhos, quadril e joelhos, que foi creditada ao decréscimo do corticoide. Também ocorreu alteração das provas de função hepática, relacionadas ao uso da acitretina, em função de sua hepatotoxicidade. Portanto, reduziu-se a dose do fármaco para $10 \mathrm{mg} /$ dia e se adicionou etanercepte $50 \mathrm{mg} / \mathrm{semanais}$, com finalidade de compensar esta redução e de melhorar o comprometimento articular, em virtude da sua eficácia na artrite psoriasica. Setenta e cinco dias após essa mudança no esquema terapêutico, a paciente mantém-se com o quadro cutâneo estável, refere remissão das manifestações articulares e apresenta melhora da função hepática.

\section{Discussão}

A psoríase é uma doença crônica autoimune que acomete $2-3 \%$ da população mundial.8 A afecção é caracterizada por inflamação, hiperproliferação dos queratinócitos, alterações em sua diferenciação e sua vascularização. ${ }^{9,10}$ As células epiteliais se maturam de forma acelerada e, antes da descamação dos corneócitos, chegam à camada superficial, onde se acumulam e geram as lesões características da doença. ${ }^{11}$

Acredita-se em predisposição genética relacionada a mutações em complexos gênicos como o PSORS. Um dos seus loci, o PSORS1, é responsável por até $50 \%$ dos

casos confirmados de transmissão genética. Este loci codifica parte do Antígeno Leucocitário Humano (HLA) do cromossoma 6p. ${ }^{12,13}$ Alguns tipos 

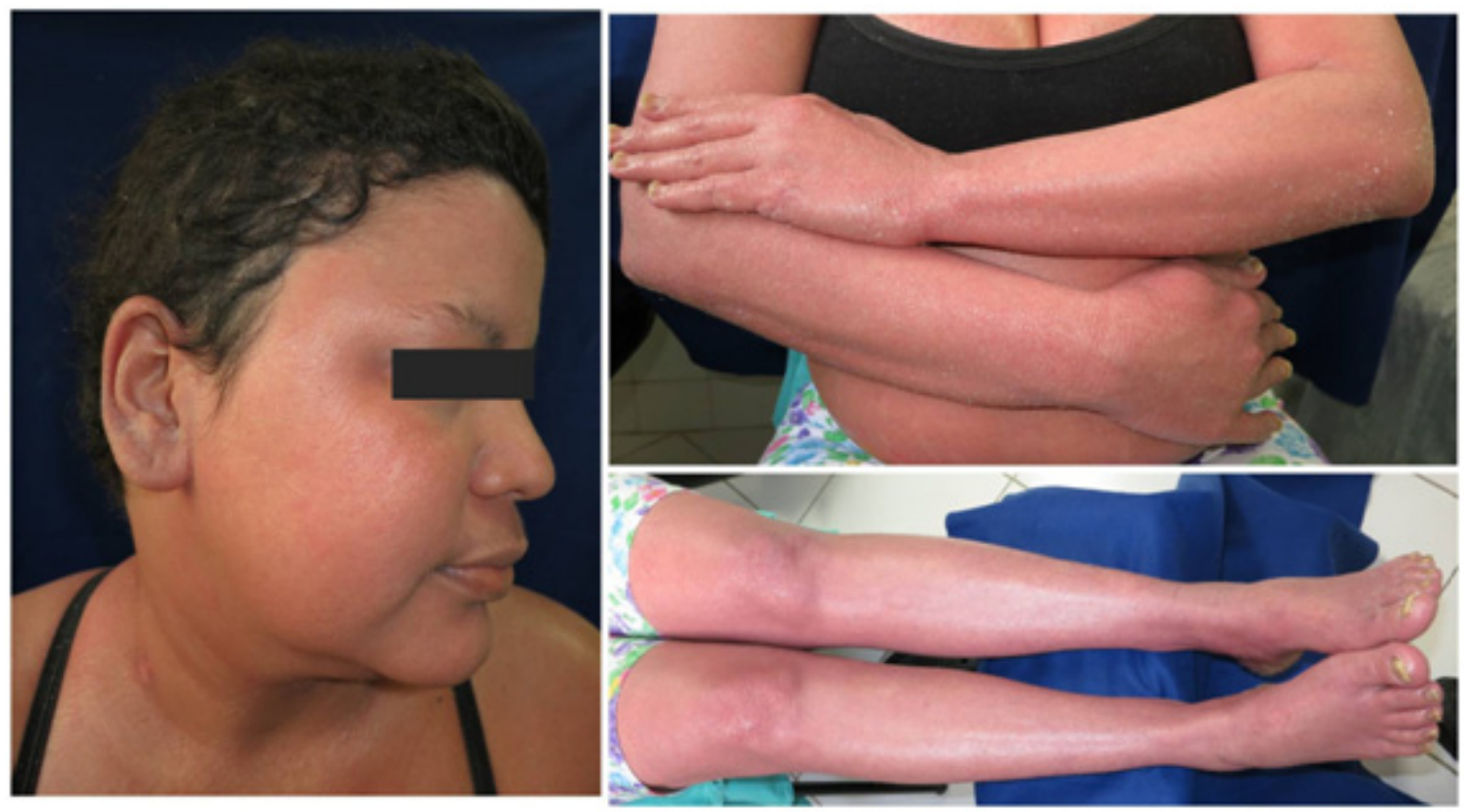

Figura 3: Paciente no $90^{\circ}$ dia de tratamento, com melhora do quadro cutâneo e reconstituição de fâneros.

de HLA (proteínas encarregadas de reconhecer e apresentar antígenos) parecem estar associados à psoríase: HLAB13, HLA-B17, HLA-B37, HLA-Bw16, HLABw57 e HLA-DR7. O HLA-Cw6 está presente em mais de $80 \%$ dos casos de psoríase de início precoce e aumenta em 13 vezes o risco de se desenvolver psoríase. $^{13,14}$

O curso da doença é mediado por linfócitos Th17, que são estimulados por Interleucina-23 (Il-23) e produzem Il-6, 17, 21, 22, bem como por linfócitos Th1, que sintetizam Il-2 e INF- $\gamma .10,14,15$ A Il-22 está implicada na proliferação dos queratinócitos e no aumento da inflamação. ${ }^{13}$ Foi relatado o possível envolvimento de agonistas do receptor do fator de crescimento epitelial (EGFR) ${ }^{10}$ e já foram identificadas várias citocinas, como a TNF- $\alpha$, nas placas psoriásicas. ${ }^{6,16}$

Discute-se o gatilho para o desenvolvimento da psoríase e se acredita que mais de um mecanismo esteja relacionado. Uma hipótese defende que traumas cutâneos gerariam lesão psoriásica local (fenômeno de Koebner) e induziriam os queratinócitos a liberarem citocinas Tais citocinas ativariam linfócitos $\mathrm{T}$, que produziriam mais mediadores e amplificariam a inflamação. Em caso de trauma, outra proposição é a interação das células epidérmicas de Langerhans com os linfócitos T Helper, estimulando a liberação de citocinas que, só então, ativariam os queratinócitos.
Uma terceira hipótese argumenta que a lesão típica do fenômeno de Koebner é consequência do ataque inapropriado de linfócitos T Killer aos queratinócitos. ${ }^{9}$

Cerca de $90 \%$ dos casos manifestam-se com placas simétricas, eritematosas, descamativas, localizadas principalmente em superfícies extensoras, couro cabeludo e região lombar. $^{8}$

A psoríase eritrodérmica, acometendo mais de $90 \%$ ou de $75 \%{ }^{17}$ da superfície corporal, representa até $23 \%$ de todas as eritrodermias, mas engloba apenas $1-2,5 \%$ dos casos da doença. ${ }^{16,17} \mathrm{Na}$ maioria dos relatos, tem curso crônico e progressivo e deriva da falta de tratamento adequado da psoríase. A forma aguda costuma ocorrer durante o tratamento, seja por intolerância, interrupção brusca das drogas ou por fatores externos, como infecções, estresse emocional, trauma e consumo excessivo de álcool. Em casos raros, o quadro incide de novo, já na primeira aparição da psoríase. ${ }^{16-18}$ Após várias abordagens, a paciente do presente caso recordou remoto episódio, quando discretas placas surgiram em suas dobras cubitais e regrediram espontaneamente, sem qualquer reincidência até o presente. Entretanto, o quadro relatado é típico da rara forma aguda de novo. O estresse emocional por problemas familiares foi considerado o principal desencadeador.

Este caso ilustra um exemplo de evolução tão rápida, que se perdem as peculiaridades da psoríase, 
dificultando o diagnóstico. As manifestações cutâneas encontradas abrangiam: intenso edema, eritema, descamação e prurido generalizados, além de alopecia e de distrofia ungueal.

A eritrodermia predispõe a pele à colonização bacteriana, especialmente por patógenos como Staphylococcus aureus. ${ }^{16,17}$ Essa complicação ocorreu com a paciente, justificando o controle rigoroso com antibioticoterapia para se evitar a sepse em indivíduo imunodeprimido por corticóide.

Do mesmo modo, também se observaram alterações sistêmicas, como a desregulação termostática. Os mecanismos causadores são a hipertermia decorrente da vasodilatação cutânea, a hipohidrose gerada pela obstrução de glândulas por escamas e o aumento do metabolismo basal pelo alto turn over celular. ${ }^{16}$ Isto explica a dificuldade em se definir se a febre é secundária a infecção ou é apenas parte da doença de base. Como nesses pacientes a infecção pode evoluir com péssimo prognóstico, múltiplos antibióticos são empregados, favorecendo o desenvolvimento de bactérias resistentes, como sucedido com a paciente.

$\mathrm{O}$ aumento de fluxo cutâneo e a perda de água acarretam taquicardia, presente durante toda a internação da paciente. Nos idosos, tal aceleração de ritmo pode precipitar insuficiência cardíaca. ${ }^{16} \mathrm{~A}$ alta replicação celular despende muita energia, ${ }^{17}$ que, associada a alterações hidroeletrolíticas, é responsável por edema e atrofia muscular. ${ }^{16}$ A presente paciente apresentou exacerbação do tremor essencial, que também pode ter sido complicado pelo uso prolongado de corticoide. Outro achado foi a anemia, relacionada à doença crônica. ${ }^{16}$

Frente à eritrodermia, são necessárias medidas de suporte, como hidratação, oferta de dieta hipercalórica e hiperproteica e uso de anti-histamínicos sedativos. ${ }^{16}$

Quanto à abordagem específica, o uso de corticosteroides sistêmicos é controverso, devido ao risco de efeito rebote. ${ }^{17}$ Preconiza-se a administração de drogas de ação rápida, como a ciclosporina e o infliximab. ${ }^{17,18} \mathrm{~A}$ ciclosporina inibe as funções dos linfócitos T, bem como a síntese de mediadores inflamatórios, especialmente, a Il-2. ${ }^{19}$ É o fármaco de escolha para a psoríase eritrodérmica aguda, porém não é boa opção para manutenção em vista de seu potencial nefrotóxico e hipertensivo. ${ }^{6,16,19}$ Para utilizá-la por longo período (cerca de mais de 16 semanas), recomenda-se o acréscimo de outra droga, como o retinóide acitretina ou o metrotexate, visando à redu- ção gradativa do primeiro fármaco. ${ }^{16,17,20} \mathrm{~A}$ acitretina modula a proliferação e a diferenciação celular, induz a apoptose, produz efeitos antiinflamatórios e não é imunossupressor, embora exija ao menos 1-2 semanas de uso isolado para gerar resposta. ${ }^{13,16,17}$ Além disso, seu emprego poder provocar dislipidemia, alteração das provas de função hepática, teratogenicidade e aumento da concentração plasmática da ciclosporina. ${ }^{13,16,17,20} \mathrm{O}$ metrotexate começa a atuar mais precocemente, porém é hepatotóxico. ${ }^{6,16,17}$ Outra opção é combinar uma das drogas à fototerapia. A combinação clássica é acitretina e UVB ou PUVA (UVA associado a composto psoralênico), já que o retinoide confere benefício contra o câncer de pele e o fotodano, causados pela fototerapia. ${ }^{20} \mathrm{~A}$ paciente negava qualquer morbidade prévia e só apresentou picos hipertensivos em dois dias, sem necessitar de interferência na medicação. $\mathrm{O}$ uso da ciclosporina proporcionou melhora progressiva, sobretudo após a associação com a acitretina, que possibilitou a redução da corticoterapia. Mas, diante da alteração nas provas de função hepática, diminuiu-se a dose da acitretina, obtendose boa resposta.

Em caso de gravidade somada a: falha; contraindicação ou intolerância a drogas anteriormente administradas, ainda seria viável recorrer a agentes biológicos, como os antagonistas de TNF. ${ }^{6,11,14,20}$ Os agentes podem ser usados em monoterapia e combinados a fototerapia por UVB ou drogas convencionais. ${ }^{6} \mathrm{Um}$ exemplo é o etanercepte, receptor para o TNF ligado à fração $\mathrm{Fc}$ de Imunoglobulina $\mathrm{G}$, capaz de bloquear os efeitos de TNF circulante ou ligado a células efetoras. O etanercepte foi prescrito no caso para contrabalançar a redução da acitretina e para atuar nas manifestações articulares, tendo em vista sua eficácia na artrite psoriásica. O resultado esperado foi alcançado, pois, mesmo com a redução da acitretina, o quadro cutâneo não retrocedeu e a artralgia remitiu. Os agentes biológicos incluem, ainda, o infliximab e o adalimumab, exemplos de anticorpos antiTNF. ${ }^{11,13,15}$ Uma segunda geração de anticorpos em estudo tem como representante o golimumabe. ${ }^{11,13,15}$ Há também os inibidores de células T: efalizumab e alefacept; e os bloqueadores de IL-12 e IL-23: ustequinumab e briakinumab. ${ }^{6,11,13,15}$ Para usar tais drogas, é preciso descartar a concomitância de infecções ativas, tuberculose latente, doenças desmielinizantes, neoplasias e insuficiência cardíaca avançada. ${ }^{13}$ Outra classe de anticorpos a se considerar são os antiEGFR, como panitumumab e cetuximab. ${ }^{10}$ 


\section{Conclusões}

O presente caso representou um desafio na busca pelo diagnóstico correto, tratamento direcionado e controle de possíveis e graves complicações. A biópsia foi fundamental para o esclarecimento etiológico. Até o estabelecimento do diagnóstico definitivo, foram utilizadas medicações inadequadas, como a corticoterapia sistêmica, cuja suspensão foi difícil, retardando a melhora da paciente. Além disso, as complicações hidroeletrolíticas e infecciosas provocaram o supertratamento de infecções e o surgimento de bactérias multirresistentes. Após o início do tratamento específico com drogas consagradas como a ciclosporina e a acitretina, houve melhora da paciente, possibilitando a redução da corticoterapia. Além delas, a introdução do etanercepte, foi fundamental para a remissão das manifestações articulares, demonstrando a importância da inclusão dos agentes biológicos no arsenal terapêutico da psoríase.

\begin{abstract}
Erythroderma is a rare syndrome, responsible for diffuse erythema and scaling, affecting more than 80 or $90 \%$ of the body surface. It is potentially serious, because of the association with electrolyte disturbances and bacterial colonization. Among the etiological causes are present: primary dermatological diseases, allergic reaction to certain drugs, systemic diseases, and neoplasms. In this case report, we illustrate an example of severe and acute erythroderma initially treated with systemic steroids. The skin biopsy indicated the diagnosis of erythrodermic psoriasis, which responded well to treatment with cyclosporine, acitretin and etanercept. Based on this report, we reviewed the literature on the causes of exfoliative dermatitis and discussed the management of severe cases of psoriasis.
\end{abstract}

Key-words: Dermatitis, Exfoliative. Psoriasis. Cyclosporine. Acitretin. Biological Agents.

\section{Referencias Bibliográficas}

1. Fernandes NC, Pereira FSM, Maceira JP, Cuzzi T, Dresch TFLR, Araújo PP. Eritrodermia: estudo clínico-laboratorial e histopatológico de 170 casos. An Bras Dermatol. [serial on the Internet]. 2008 Dec [cited 2013 July 11] ; 83: 526-32. Available from: http://www.scielo.br/scielo.php?script=sci_arttext \&pid=S0365-05962008000600005\&lng=en. http://dx.doi.org/ 10.1590/S0365-05962008000600005.

2. Vasconcellos C, Domingues PP, Aoki V, Miyake RK, Savaia N, Martins JEC. Erythroderma: analysis of 247 cases. Rev Saúde Pública. 1995; 29: 177-82.

3. Salami TA, Enahoro Oziegbe O, Omeife H. Exfoliative dermatitis: patterns of clinical presentation in a tropical rural and suburban dermatology practice in Nigeria. Int J Dermatol. 2012; 51:1086-9.

4. Kondo RN, Gon ADS, Minelli L, Mendes MF, Pontello R. Dermatite esfoliativa: estudo clinico-etiologico de 58 casos. An Bras Dermatol. 2006;81:233-7.

5. Bolognia JL, Jorizzo JL, Rapini RP. Em: Dermatologia. $2^{\mathrm{a}}$ edição. Rio de Janeiro: Elsevier; 2011. p. 149-58.

6. Viglioglia PA. Eritrodermias. Dermatol Argent. , 2005; 11: 204 10.

7. Sanches Jr JA, Moricz CZM de, Festa Neto C. Processos linfoproliferativos da pele: parte 2 - linfomas cutâneos de células T e de células NK. An Bras Dermatol. 2006; vol. 81 [online, acessado em 6 abr 2013].
8. Chiricozzi A, Saraceno R, Cannizzaro MV, Nisticò SP, Chimenti S, Giunta A. Complete Resolution of Erythrodermic Psoriasis in an HIV and HCV Patient Unresponsive to Antipsoriatic Treatments after Highly Active Antiretroviral Therapy (Ritonavir, Atazanavir, Emtricitabine, Tenofovir). Dermatology. 2012; 225:333-7.

9. Peters BP, Weissman F, GGill MA. Pathophysiology and treatment of psoriasis. Am J Health System Pharm. 2000;57: 64559.

10. Nishizawa A, Satoh T, Yokozeki H.Erythrodermic psoriasis improved by panitumumab, but not bevacizumab. Acta Derm Venereol. 2012; 92:360-1.

11. Gonçalves PR. Desfechos relatados pelo paciente (DRP) com Psoríase moderada a grave em tratamento com imunobiológicos. [dissertação]. Curitiba: Universidade Federal do Paraná, Ciências Farmacêuticas, Área de Concentração Medicamentos, Insumos e Correlato, Departamento de Farmácia, Setor de Ciências da Saúde, 2013.

12. Cuesta-Montero L, Belinchón I. Conectivopatías y psoriasis. Actas Dermo-Sifiliogr. 2011; 102: 487-97.

13. Esteves IFC. Psoríase: recentes avanços na compreensão da doença e sua terapêutica [Dissertação de Mestrado]. Lisboa, Faculdade de Ciências e Tecnologias da Saúde - Universidade Lusófona de Humanidades e Tecnologias 2013.

14. Retinoids in the Treatment of Psoriasis. In: Sommerburg O; Siems W; Kraemer K., editores ( $1^{\underline{a}}$ ed). Carotenoids and Vitamin A in Translational Medicine (Oxidative Stress and Disease). Boca Raton: Taylor \& Francis Group; 2013. P:55-75. 
15. Souza AWS de, Mesquita Júnior D, Araújo JAP, Catelan TTT, Cruvinel WM, Andrade LEC, et al. Sistema imunitário: parte III. O delicado equilíbrio do sistema imunológico entre os pólos de tolerância e autoimunidade. Rev Bras Reumatol. [serial on the Internet]. 2010 Dec [cited 2013 July 12]; 50: 665-79. Available from: http://www.scielo.br/scielo.php?script =sci_arttext\&pid=S0482-50042010000600007\&lng=en. http:/ /dx.doi.org/10.1590/S0482-50042010000600007

16. Ferrándiz C, Carrascosa JM, Bielsa I. Eritrodermia psoriásica. Piel (Bar c., Ed. impr.) 2011; 26:18-24.

17. Rosenbach M, Hsu S, Korman NJ, Lebwohl MG, Young M, Bebo BF Jr et al. Treatment of erythrodermic psoriasis: From the medical board of the National Psoriasis Foundation. J Am Acad Dermatol. 2010; 62:655-62.
18. Teran CG, Teran-Escalera CN, Balderrama C. A severe case of erythrodermic psoriasis associated with advanced nail and joint manifestations: a case report. J Med Case Rep. 2010; 15:179.

19. Borghi A, Corazza M, Mantovani L, Bertoldi AM, Giari S, Virgili A.Prolonged cyclosporine treatment of severe or recalcitrant psoriasis: descriptive study in a series of patients. Int $\mathrm{J}$ Dermatol. 2012;51:1512-6.

20. Maia CPA. Consenso Brasileiro de Psoríase. In: Dermatologia SBd. 2 ed. Rio de Janeiro: SBD; 2012 